\title{
Perceived Supervisor Support and Employee Turnover Intention: The Moderating Effect of Employment Tenure
}

\author{
W.D.N.S.M Tennakoon ${ }^{1}$ \& U.L Herat ${ }^{2}$ \\ 1,2 Department of Business Management \\ Faculty of Business Studies \& Finance \\ Wayamba University of Sri Lanka \\ Kuliyapitiya \\ SRI LANKA \\ tennakoon@wyb.ac.lk ${ }^{1}$, ulherat@yahoo.com ${ }^{2}$
}

\begin{abstract}
The influence of supervisory behavior on employee turnover intention has long been discussed by HR scholars. Yet, moderating and mediating relationships of this setting have been addressed seldomly. The central focus of this study was to test the moderating effect of employment tenure on to the relationship between perceived supervisory support and employment turnover intention. The quantitative inquiry adopts the survey method. Perceived supervisory support was the independent variable and the employee turnover intention was the dependent variable. Employment tenure (short vs. long) was assumed to be the moderating variable of the said relationship. The twenty-itemed survey instrument recorded $0.7-0.71$ reliability score. The answers were ranked against a seven point Likert scale where 1 denotes strongly disagree and 7 denotes strongly agree. Data from the respondents $(n=135)$ was analyzed using mainly the ANOVA, correlation and multiple regression analysis. Results point out a significant negative relationship between perceived supervisory support and employee turnover intention. Importantly, it is revealed that there is a significant moderating effect by employment tenure on the association between main variables concerned. The theoretical implication of moderating role of employment tenure and the practical implication of offering extended support for short tenured employees concluded the study.
\end{abstract}

Keywords: Perceived supervisor support, employee turnover intention, employment tenure, moderating effect

\section{INTRODUCTION}

Labor turnover yet is a burning issue for many organizations despite to the countless organizational initiatives to lessen the effect of it. It has both direct and indirect costs to an organization.
Turnover is defined as 'voluntary terminations of members from organizations' (Hom \& Griffeth, 1994). According to Foon, CheeLeong \& Osman (2010), turnover is 
very much common to every type, size $\&$ level of the organization. The apparel industry is playing a vital role in Sri Lankan economy (Central Bank of Sri Lanka, 2016). According to Dheerasinghe (2009), Sri Lankan apparel industry is facing problems in developing and maintaining the required manpower. There are many variables which does affect the employee turnover in organizations. They are pay, integration, supervisory support, centralization, instrumental communication, formal communication, upward mobility, and distributive justice, length of service, age, education, occupation, marital status, and sex etc. Review of existing literature highlights the impact of perceived supervisory support on turnover intention. This has been researched to be the first most influential factor of employee turnover (Thanocoody et al, 2009; Dawley et al, 2007; Liyanage \& Galhena, 2002) Several studies have found that the supervisory support is the best predictor of turnover intention. Nevertheless, practitioners suggest a variation in this relationship with respect to the employment tenure (i.e. service period) of the employee for which empirical evidences are inaccessible. Thus, the present study was designed to test whether employment tenure of employees moderates the relationship between the perceived supervisor support and turnover intention of employee.

\section{Theoretical Background}

The performance of the human capital within an organization is the prime determinant of the organizational succession (Robbins \& Jude, 2012).
Thus, human resource is needed to be utilize, direct, and motivate in an acceptable way (Sujeewa, 2011). Lesabe and Nkosi (2007) argue that none of the organization can perform successfully in the competitive world without undivided commitment of employees. Organizations thus need to realize that if employees are well managed, success is inevitable (Hellriegel et al, 2004).

\section{Turnover intention}

Turnover is undoubtedly a severe issue for majority of organizations. Among the different definitions, Tett and Meyer (1993) defined employee turnover as the voluntary termination of an individual's employment with a given company. Regardless of the fact that who initiate it, both employees and firms get affected by the intolerable level of employee turnover (Brown et al, 2005).

Turnover intention is known as employee's intention to find a new job with another employer in near future (Medina, 2012). It results in transferring the employees across the organizational boundaries (Macy \& Mirvis, 1976). Turnover intention; the main symptom of turnover is affected by several factors (Bluedorn, 1982; Steel \& Ovalle, 1984; Lee \& Heard, 2000). Factors affecting turnover intention today have become increasingly complex. The effect of working environment, salary level, supervisor support and coworker relationship count to be the top most contributing factors to turnover intention (Avey, Luthans \& Jensen, 2009). Additionally, turnover could be a disruption to worker \& to the workplace in the forms of need to learn new job-specific skills, need to find 
different career prospects, lose jobspecific skills, suffer disruption in production and incur the costs of hiring \& training new workers (Liyanage \& Galhena, 2002). As to Nawaz, Rahman \& Siraji (2009) working condition, supervisor behavior, job satisfaction, and organizational commitment are treated to lead the labor turnover. It can also be resulted from job satisfaction, manager's attitude, organizational culture, personal problems, job content and financial rewards (Saeed, Mussawar, Lodhi, Iqbal, Nayab and Yaseen, 2013). Supervisory behavior found to be having a direct impact on turnover intention (Thanocoody et al, 2009; Dawley et al, 2007; Liyanage \& Galhena, 2002). With respect to garment industry, this is even critical as the collaboration and coordination between supervisor and the employee are highly demanding.

\section{Supervisory support}

Supervisors are considered as the first level managers who shoulder the prime responsibility of leading work groups in organization (Elangovan \& Karakowsky, 1999; Noe, 2008). Along with the changes in business context, the role of the supervisors has also changed where contemporary supervisors are treated as catalyst of organizational succession rather a reporting and monitoring mechanism (Ismail, et al., 2010). Perception gives rise to certain attitudes and relationships because a person's opinion and points of view are shaped by his/her perceptions naturally (Lok, Westwood, Crawford, 2005). The supervisory support for employees may take different forms. Among them, the role of immediate supervisor is treated as the most critical. They directly convey the organizational intentions to their employees (Dawley et al. 2007). Tuzun and Kalemci (2012) showed that supervisor-related perceptions and attitudes could shape organizational -related perceptions and attitudes.

Employees deserve that their supervisor will provide all the necessary support to continue their activities and to make them more engaged with their work. Employee engagement and supervisory support found to be highly related (Swanberg et al., 2011). Munn, Barber and Fritz et al. (2007) found that supervisor support is the best predictor of job satisfaction \& intention to quit. The way employees perceive their supervisor's behavior proven to be affecting their intention to quite the job. By exhibiting supportive behavior supervisors can easily manage subordinates' emotions. This intern can be used to control the turnover intention of employees (Dawley et al., 2007). Supervisory support associates with career satisfaction of employees (Wickramasinghe \& Jayaweera, 2010). Divergent ideas between supervisors and employees lead to conflict among them which finally results in intention to quit the job (West, 2007). Perceived supervisory support tested to be a mediating the relationship between stress and intention to quit and also directly affecting the turnover intention (Firth et al., 2003).

Bawsd on the presented empirical evidenced it is hypothesize that the perceived supervisor support affect the turnover intention of employees. 
H1: Perceived supervisory support significantly relates with employee turnover intention.

\section{Employment tenure}

Employment tenure is time period that a person spent on the job in an organization (Nawaz, 2009). It is simply based on the time period in between starting date and last date at work. Employment tenure reported to be negatively correlated with voluntary employee turnover. Longer the stay in an organization greater the commitment of employees (Becker, 1960). With respect to Sri Lankan garment industry, most female workers tend to terminate their employment tenure due to marriage (Dheerasinghe, 2003). Some are leaving the organization for foreign employment. Short employment tenures damages the consistency of the production \& operations. As a result organizations may need to comprise their profits and to bear severe losses in terms of both monetary and nonmonetary assets such as good will and reputation.

The beginners usually have less knowledge and experience regarding the operations of an organization.
They are purely new to the organizational culture too. It takes some times for them to become experts of their job and that period depends on several factors including learning ability of the employee. Immediate supervisor of new comers has a greater role to be played in order to facilitate her/him to adjust to new context. Absence of this facilitation causes employees to terminate their employment tenure. But this won't be a problem for older employees who are by then well aware about their job and the organization. Practical evidences of the researches with the industry support the similar nature of association between employment tenure and turnover intention. Employees with shorter tenures tend to terminate their employment easily than employees who have spent longer/ considerable time at the organization. Hence, it is assumed that employment tenure moderate the association between perceived supervisory support and turnover intention.

H2: Employment tenure moderates the relationship between perceived supervisory support and employment turnover intention.

\section{Research Model}

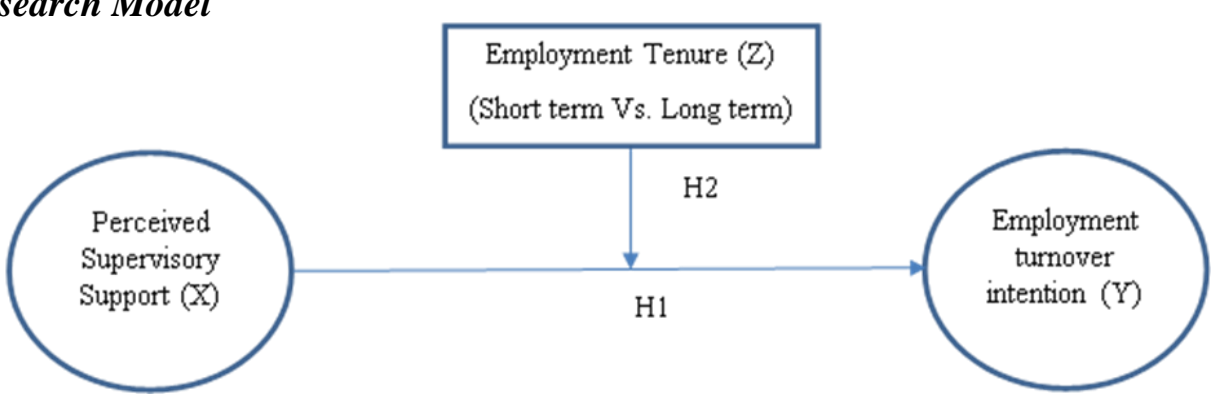

Figure 1. Research Model 


\section{METHODS}

The study applied the quantitative research approach to explore the moderating effect of employment tenure on to the relationship between perceived supervisor support and turnover intention. Perceived supervisor support was operationalized using supervisor's concern, behavior of supervisor, stress caused by supervisor, and status of supervisor while turnover intention was measured in terms of intention to quit job, and search of new job opportunities. Employment tenure was categorized into two main categories namely less than or equal 6 months and more than 6 months. Garment Industry; the largest labor intensive industry which makes highest contribution to GDP was selected after reviewing the very high labor turnover of it (Sandeepanie \& Ubayachandra, 2015). The sample was drawn from a well-established \& reputed garment manufacturing organization where favorable Human Resource development practices are in action. A questionnaire was used for collecting data. The instrument consists of 20 items. The answers were ranked against a seven point Likert scale where 1 denotes strongly disagree and 7 denotes strongly agree. The reliability analysis revealed Cronbach's Alpha value is ranging between 0.70-0.71 for the two groups of respondents. That ensured the reliability of the instrument to collect the data from the sample. The questionnaire was hand delivered to the respondents which was later collected by researchers themselves. The Sinhala version of the questionnaire was used to affect the response ratio. The sample consists of randomly selected 150 Sewing Machine Operators (SMOs). Among them fifty (75) SMOs have spent more than 6 months and the rest have spent less than 6 months in their service. Hundred and fifty (150) questionnaires were distributed among the respondents initially while hundred and thirty-eight (138) of them were returned. Out of the received questionnaires, three (03) were disregarded due to incompletion. The collected data were analyzed using the Pearson's correlation coefficient, partial correlation, and least square regression analysis.

\section{FINDINGS}

The sample demonstrated vivid demographic profiles (refer table 1).

Table 1. The Demographic Profile of the Respondents

\begin{tabular}{l|lll|}
\hline \multicolumn{2}{l}{ Features } & Frequency & Percentage \\
\hline Age & 1. Below 20 years & 39 & 29 \\
& $2.20-25$ & 35 & 26 \\
\cline { 2 - 3 } & &
\end{tabular}




\begin{tabular}{|c|c|c|c|}
\hline & 3. $26-30$ & 32 & 24 \\
\hline & 4. $31-35$ & 19 & 14 \\
\hline & 5. $36-40$ & 06 & 04 \\
\hline & 6. Above 41 & 04 & 03 \\
\hline Total & & 135 & $100 \%$ \\
\hline Gender & 1. Male & 18 & 13 \\
\hline & 2. Female & 117 & 87 \\
\hline Total & & 135 & $100 \%$ \\
\hline Marital & 1. Married & 91 & 67 \\
\hline & 2. Unmarried & 44 & 33 \\
\hline Total & & 135 & $100 \%$ \\
\hline Tenure & $\begin{array}{l}\text { 1. Short term }(=<6 \\
\text { months })\end{array}$ & 65 & 48 \\
\hline & $\begin{array}{l}\text { 2. Long term ( }>6 \\
\text { months) }\end{array}$ & 70 & 52 \\
\hline Total & & 135 & $100 \%$ \\
\hline
\end{tabular}

As depicted by table 1 , majority ( $87 \%$ ) of respondents were female employees. The sample comprised of fairly equal number of employees for both short employment tenure (48\%) and long employment tenure (52\%). Table 2 exhibits the summary statistics of the demographic factors of the respondents. 
Table 2. Summary Statistics

\begin{tabular}{|l|r|r|r|r|}
\hline & Age & Gender & Civil_Status & \multicolumn{1}{|c|}{ Tenure } \\
\hline $\mathrm{N}$ & 135 & 135 & 135 & 135 \\
Mean & 2.48 & 1.87 & 1.3259 & 1.5185 \\
Median & 2.00 & 2.00 & 1.0000 & 2.0000 \\
Mode & 1 & 2 & 1.00 & 2.00 \\
Std. Deviation & 1.321 & .341 & .47047 & .50152 \\
\hline
\end{tabular}

According to the statistics, majority represents below 20 years age category ( $1=$ below 20 years). It implies most of the are just beginners of their career. Females dominates the sample $2=$ females). This is obvious as garment industry in general employs more females than males. Again the sample comprised of more married employees than unmarried (1=married) indicating changing the job is a more serious concern for them than others.

So as to test the differences among two groups of employees with respect to perceived supervisor support, a test of ANOVA was carried out of which the results are shown by table 3 .

Table 3. Results of ANOVA

\begin{tabular}{|ll|r|r|r|r|r|}
\hline & \multicolumn{1}{c|}{$\begin{array}{c}\text { Sum of } \\
\text { Squares }\end{array}$} & Df & Mean Square & F & \multicolumn{1}{c|}{ Sig. } \\
\hline Perceived & Between Groups & 6.493 & 1 & 6.493 & 11.422 & .001 \\
supervisory & Within Groups & 75.608 & 133 & .568 & & \\
support (x) & Total & 82.101 & 134 & & & \\
Turnover & Between Groups & 46.627 & 1 & 46.627 & 24.900 & .000 \\
intention & Within Groups & 249.049 & 133 & 1.873 & & \\
(y) & Total & 295.676 & 134 & & & \\
\hline
\end{tabular}

The results of the one way ANOVA test shows a significant difference between short tenured employees and long tenured employees with respect to both perceived supervisor support and turnover intention. It indicates that these two groups of employees are not holding the identical views regarding how they are been treated by their supervisors and their idea to remain in the organization under any circumstance.

To establish that the perceived supervisory support and employee turnover intention is related, a correlation analysis is conducted. This resulted in a moderate negative relationship between variables concerned(table4) 
Tale 4. Results of Correlation Analysis

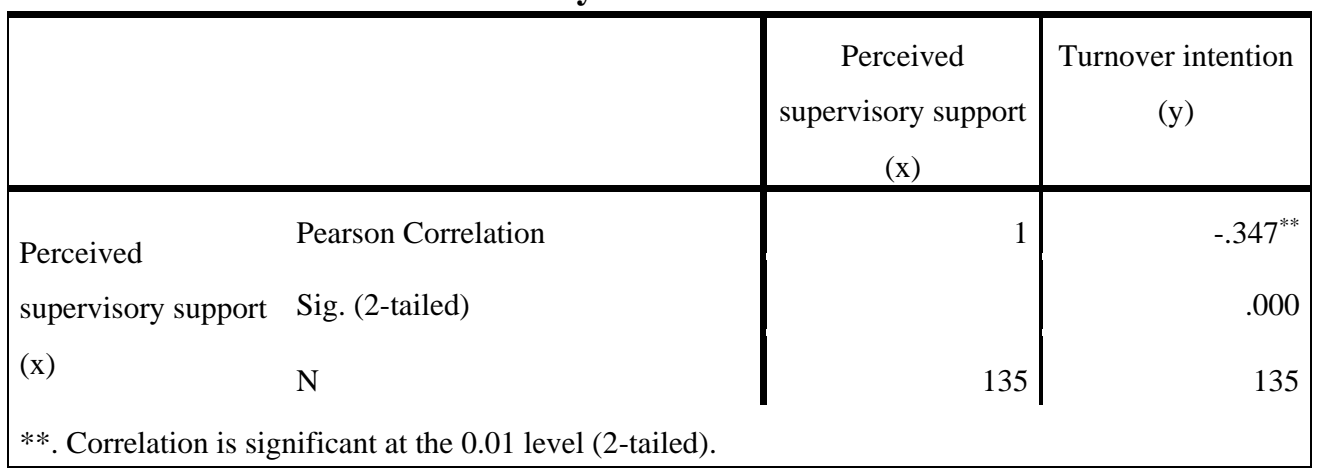

Based on the available statistical evidences it is concluded that perceived supervisory support is significantly and negatively related with employee turnover intention $(\mathrm{r}=$ -0.347). The results complies with the previous findings in this realm (Ismail, et al., 2010; Firth et al., 2003; Swanberg et al., 2011; Munn, Barber and Fritz et al., 2007). In practice, immediate supervisor plays a significant role in the job related behavior of an employee as he who is the primary source of influencer/motivator for any employee. In absence of healthy relationship between them, both parties may develop ill feeling towards other party. Then they found difficult to remain jointly at work resulting withdrawal of one party, usually the less-privileged ones: employees.

The main focus of this study was to test the moderating effect of employment tenure in to the relationship between perceived supervisory support and employee turnover intention. Once the said relationship is established, next it is required to test the moderating effect

of employment tenure. A multiple regression is performed to test the moderating effect where

interaction effect should be significant in case of significant moderating effect.

The moderation effect is tested with multiple regression analysis (OLS), where all predictor variables and their interaction term are centered prior to model estimation to improve interpretation of regression coefficients. A single regression equation forms the basic moderation model:

$Y=i_{5}+\beta_{1} X+\beta_{2} Z+\beta_{3} X Z+e_{5}$

Where $\beta 1$ is the coefficient relating the independent variable, $X$, to the outcome, $Y$, when $Z=0, \beta 2$ is the coefficient relating the moderator variable, $\mathrm{Z}$, to the outcome when $\mathrm{X}=$ 0 , i5 the intercept in the equation, and e 5 is the residual in the equation. The 
regression coefficient for the interaction term, $\beta 3$, provides an estimate of the moderation effect.
If $\beta 3$ is statistically different from zero, there is significant moderation of the $\mathrm{X}-\mathrm{Y}$ relation in the data (Aiken \& West, 1991 as cited in Fairchild, A.J. \& MacKinnon, D.P., 2009).

Table 5. Results of Regression Analysis

Coefficients $^{\mathrm{a}}$

\begin{tabular}{|c|c|c|c|c|c|c|c|c|}
\hline \multirow[t]{2}{*}{ Model } & \multicolumn{2}{|c|}{$\begin{array}{c}\text { Unstandardized } \\
\text { Coefficients }\end{array}$} & \multirow{2}{*}{$\begin{array}{c}\begin{array}{c}\text { Standardized } \\
\text { Coefficients }\end{array} \\
\text { Beta }\end{array}$} & \multirow[t]{2}{*}{$\mathrm{t}$} & \multirow[t]{2}{*}{ Sig. } & \multicolumn{3}{|c|}{ Correlations } \\
\hline & B & $\begin{array}{l}\text { Std. } \\
\text { Error }\end{array}$ & & & & $\begin{array}{l}\text { Zero- } \\
\text { order }\end{array}$ & Partial & Part \\
\hline (Constant) & 4.581 & 2.043 & & 2.242 & .027 & & & \\
\hline SUP_SUP & .190 & .493 & .100 & .386 & .007 & -.347 & .034 & .030 \\
\hline Tenure & .877 & 1.300 & .296 & .675 & .005 & -.397 & .059 & .052 \\
\hline Interaction & -.438 & .304 & -.806 & 1.440 & .015 & -.475 & -.125 & -.110 \\
\hline
\end{tabular}

a. Dependent Variable: LTO_sum

The regression model of four predictors, constant, perceived supervisory support, employment tenure and interaction is significant (ref. appendix). Model summary statistics indicates that $48 \%$ of the dependent variable's total variance is explained by the regression model (ref. appendix). Table 5 presents the coefficients for the predictors. Accordingly, all predictors are significant (ref. table 5). Especially, the interaction component is significant at $95 \%$ confidence level ( $\mathrm{P}$ $<0.05=0.015)$. This implies there is a significant moderating effect by employment tenure in to the relationship between perceived supervisory support and employee turnover intention. The interaction coefficient is negative which indicates that shorter employment tenured employees are likely to develop turnover intention than that of longer tenured workers as a result of poor perceived supervisory support. Experienced workers can aid themselves in any job related matter. In long term supervisory support may not be that much essential in completing the job demands. In contrast, junior workers with shorter employment tenures have to depend more on his/her supervisor while fulfilling the job demands. Hence, it is established that hypothesized relationship for moderating effect $(\mathrm{H} 2)$ can be accepted as significant.

Findings support the existing literature that claim the moderating effect of employment tenure (Nawaz, 2009). 


\section{CONCLUSION}

The study was aimed at testing moderating effect of employment tenure on employee turnover intention caused by the perceived supervisory support. The results revealed that the tested moderating effect is significant. Employees whose employment tenure is short i.e. less than 6 months tend to be greatly affected by negative perceived supervisory support. Consequently, turnover intention is high among short tenured employees than the long tenured employees. The findings of the study support the

\section{REFERENCES}

Avey,J.B.,Luthans,F., \& Jensen,S (2009). Psychological capital: a positive resource for combating employee stress and turnover. Human Resource Management, 48 (5). pp. 677- 693. DOI: 10.1002/hrm.20294.

Branham, L. (2005) The 7 hidden reasons employees leave, Sound view Executive Book Summeries.www.summery.com

Brown, M. E., Treviño, L. K., \& Harrison, D. (2005). Ethical leadership: A social learning perspective for construct development and testing. Organizational Behavior and Human Decision Processes, 97, 117-134.

Dawley, D.D., Andrews, M.C., \& Bucklew, N.S., (2007).Mentoring, supervisor support, and perceive organizational support: what theoretical implication of moderating effect of employment tenure on to the relationship between perceived supervisory support and employee turnover intention. Similarly practical implications suggest employers to take necessary measures for improving the positive perceived supervisory support within the employees especially whose employment tenure is short. It is advisable for supervisors or the leaders to be more supportive to the new comers as they are new to the work setup, organizational procedures and regulations, and to the organizational culture.

matters most? .Leadership and Organization Development Journal, 29,235-247.

Dheerasinghe, R., (2009). Garment Industry in Sri Lanka Challenges, Prospects and Strategies. Staff Studies. 33(1), pp.33-72. DOI:http://doi.org/10.4038/ss.v33 i1.1246

Elangovan, A.R. and Karakowsky, L. (1999) The Effects of Trainee and Environmental Factors on Transfer of Training: A Framework for Research. Leadership and Organizational Development Journal, 20, 268275. http://dx.doi.org/10.1108/01 437739910287180

Fairchild, A.J. \& Mackinnon, D.P., (2009). A General Model for Testing Mediation and Moderation Effects. Preventive 
Science, 10(2). pp.87-99. doi:10.1007/s11121-008-0109-6.

Firth, L., Mellor, D.J., Moore, K.A. \& Loquet, C., (2004).How can managers reduce employee intention to quit? , Journal of Managerial Psychology, 19, 170187.

Hellriegel,D., Jackson, S.E., Slocum, J.W. Management, 10th Ed. Australia; Mason, Ohio : Thomson/South-Western,

Hom PW, Griffith RW (1994). Employee turnover, South Western college publishing, Cincinnati, OH pp. 200-340

Ipek Kalemci Tuzun, R. Arzu Kalemci, (2012) "Organizational and supervisory support in relation to employee turnover intentions", Journal of Managerial Psychology, Vol. 27 Issue: 5, pp.518-534, https:// doi.org/10.1108/02683941211235 418

Liyanage, D.M., \& Galhena, b.l.(2002).Determinants of Turnover Intention of Sewing Machine Operators: Case from leading Apparel Company from Matara.

Lok, P, Westwood, R., \& Crawford, J. (2005).Perceptions of organizational subculture and their significance for organizational commitment. Applied Psychology: An International Review, 54 (4), 490-514.
Medina, E. (2012). Job Satisfaction and Employee Turnover Intention: What does Organizational Culture Have to Do with It. Independent thesis Advanced level (degree of Master (One Year), Columbia University.

Mirvis, P.H., Macy, B.A. (1976). Accounting for the costs and benefits of human resource development programs: An interdisciplinary approach. Accounting, Organizations and Society 1(2-3): 179-193. http://hdl.handle.net/2027.42/218 86

Munn, E.K., Barber, C.E., Fritz, J.J. (1996), "Factors affecting the professional well-being of child life specialists", Children's Health Care, Vol. 25 pp.71-91.

Nawaz, Y., Rahman, T., Siraji, Md. N. (2009) Role of Voluntary Employee Turnover in Textile Industry of Pakistan. Master Thesis,

MSc Business Administration, School of Management, Blekinge Institute of Technology

Noe, R. A. (2008) Employee Training and Development. McGraw-Hill Irwin

Saeed, R., Mussawar, S., Lodhi, R.N., Iqbal, A., Nayab, H.H., \& Yaseen, S. (2013). Factors Affecting the Performance of Employees at Work Place in the Banking Sector of Pakistan. Middle-East Journal of 
Scientific Research 17 (9): 1200-1208, DOI: 10.5829/idosi.mejsr.2013.17.0 9.12256

Sandeepanie , M.H.R., Ubayachandra, E.G., (2015). Different Factors affecting on Employee Motivation: In Sri Lankan Apparel Manufacturing Sector, Proceedings of 8 International Research Conference, KDU. pp168

Stephen P. Robbins,Timothy.A.Judge (2012), Essentials of Organizational Behavior, 11th Edition.

Sujeewa, W.W.A.N. (2011). Relationship between Human Resource Management Practices, Non - Managerial Employee Intention to Turnover in Garment Industry in Sri Lanka. International Conference on Management, Economics and Social Sciences, Bangkok. pp 535539.

Swanberg, J.E., Mckechnie, S.P., Ojha, M.U. and James, J.B., 2011. Schedule control, supervisor support and work engagement: A winning combination for workers in hourly jobs? Journal of Vocational Behaviour, 79(3), pp. 613-624.

Thanacoody,P.R.,Batram,T.,\&

Casimir, G.,(2009).The effects of burnout and supervisory social support on the relationship between work-family conflict and intention to leave, A study of
Australian cancer workers. Journal Of Health Organization and Management, 23,53-69.

Vathsala Wickramasinghe, Mayura Jayaweera, (2010) "Impact of career plateau and supervisory support on career satisfaction: A study in offshore outsourced IT firms in Sri Lanka", Career Development International, Vol. 15 Issue: 6, pp.544-561, https://doi.org/10.1108/13620431 011084402 Permanent link to this document:

https://doi.org/10.1108/1362043 1011084402

West, L.S. (2007). Examining the relationship between employeesuperior conflict and voluntary turnover in the workplace: A comparison of companies across industries. Master of Science (Psychology), 49 pp. 7.

Yin-Fah, B. C., Foon,Y.S., CheeLeong,L., \& Osman, S. (2010). An Exploratory Study on Turnover Intention among Private Sector Employees. International Journal of Business and Management, 5 (8) 


\section{Appendix}

Model Summary ${ }^{b}$

\begin{tabular}{|l|r|r|r|r|}
\hline Model & $\mathrm{R}$ & R Square & \multicolumn{1}{|c|}{$\begin{array}{c}\text { Adjusted R } \\
\text { Square }\end{array}$} & $\begin{array}{c}\text { Std. Error of the } \\
\text { Estimate }\end{array}$ \\
\hline 1 & $.480^{\mathrm{a}}$ & .230 & .212 & 1.31833 \\
\hline
\end{tabular}

a. Predictors: (Constant), Interaction, SUP_SUP, Tenure

b. Dependent Variable: LTO_sum

ANOVA ${ }^{a}$

\begin{tabular}{|rl|r|r|r|r|r|}
\hline Model & & Sum of Squares & Df & Mean Square & F & Sig. \\
\hline & Regression & 67.999 & 3 & 22.666 & 13.042 & $.000^{\mathrm{b}}$ \\
\multirow{2}{*}{1} & Residual & 227.677 & 131 & 1.738 & & \\
& Total & 295.676 & 134 & & & \\
\hline
\end{tabular}
a. Dependent Variable: LTO_sum
b. Predictors: (Constant), Interaction, SUP_SUP, Tenure 